\title{
Seismic monitoring of urban activity in Barcelona during the COVID-19 lockdown
}

\author{
Jordi Diaz ${ }^{1}$, Mario Ruiz ${ }^{1}$, and José-Antonio Jara ${ }^{2}$ \\ ${ }^{1}$ Geo3Bcn-CSIC, c/ Solé Sabarís sn, Barcelona, Spain \\ ${ }^{2}$ Institut Cartogràfic i Geològic de Catalunya, Barcelona, Spain \\ Correspondence: Jordi Diaz (jdiaz@geo3bcn.csic.es)
}

Received: 6 November 2020 - Discussion started: 27 November 2020

Revised: 3 February 2021 - Accepted: 17 February 2021 - Published: 26 March 2021

\begin{abstract}
During the COVID-19 pandemic lockdown, the city of Barcelona was covered by a dense seismic network consisting of up to 19 seismic sensors. This network has provided an excellent tool to investigate in detail the background seismic-noise variations associated with the lockdown measures. Permanent stations facilitate comparing the seismic noise recorded during the lockdown quieting with long-term variations due to holiday periods. On the other hand, the data acquired by the dense network show the differences between sites located near industrial areas, transportation hubs or residential areas. The results confirm that the quieting of human activity during lockdown has resulted in a reduction in seismic vibrations in the $2-20 \mathrm{~Hz}$ band that is clearly higher than during holiday seasons. This effect is observed throughout the city, but only those stations not affected by very proximal sources of vibration (construction sites, industries) are clearly correlated with the level of activity denoted by other indicators. Our contribution demonstrates that seismic amplitude variations can be used as a proxy for human activity in urban environments, providing details similar to those offered by other mobility indicators.
\end{abstract}

\section{Introduction}

Connecting students with seismology is a challenge in countries not affected by strong earthquakes. In order to mitigate this problem, the SANIMS research project included the deployment of a seismic network within the city of Barcelona, with most of the instruments installed in the facilities of secondary schools (Diaz et al., 2020). The network included up to 19 seismic sensors, distributed with an inter-station spacing of $2-3 \mathrm{~km}$. The objective of the project was to acquire data of scientific interest to investigate the feasibility of ambient-noise studies based on tomographic and interferometric methods in urban environments but also to promote the knowledge about seismology and Earth sciences among high school students. The network was deployed in September 2019 , and $50 \%$ of the sites were instrumented using the low-cost Raspberry Shake devices, which provide online access to the data in real time, thus facilitating the involvement of the students. An unexpected result of this deployment has been the possibility of studying in detail the seismic-noise variations within the city of Barcelona during the quieting associated with the COVID-19 lockdown.

As background seismic vibrations (often referred to as "seismic noise") at frequencies above $1 \mathrm{~Hz}$ are mainly dominated by human activities (i.e., Díaz et al., 2017), lockdown measurements applied to mitigate the COVID-19 pandemic, including the suppression of industrial and commercial activities and movement restrictions, have had a clear effect on the seismic-noise levels. This has been reported on a global scale by Lecocq et al. (2020a), showing how the progressive implementation of restrictions in different parts of the world could be monitored using publicly accessible seismic data. Several regional studies have documented these noise variations in China (Xiao et al., 2020), India (Somala, 2020), Brazil (Dias et al., 2020), northern Italy (Poli et al., 2020) or Sicily (Cannata et al., 2021). On a local scale, Lindsey et al. (2020) have used a $\sim 5 \mathrm{~km}$ long fiber-optic cable in Palo Alto (California, USA) to acquire distributed acoustic sensing (DAS) data and analyze the seismic-noise variations during the COVID-19 pandemic. However, as far as we know, there are no studies available that explore variations in seismic noise within 
a large city during the COVID-19 lockdown period with a space between sites on the order of $2-3 \mathrm{~km}$. This contribution focuses on analyzing such variations, which can be important depending on the specific location of each site. In addition, the availability of long-term data in the permanent stations makes it possible to put the noise reduction due to the COVID-19 lockdown in Barcelona into context.

Following the increasing number of COVID-19 cases during February and early March 2020, measures to mitigate the pandemic effects started in Barcelona on Thursday, 13 March, with the cancellation of all face-to-face classes in schools and universities. The next day, the prime minister declared the state of alarm, and announced the first lockdown measures (phase 1), effective from 00:00 on Sunday, 15 March. Citizens were ordered to stay indoors, except for basic activities such as commuting to workplaces, buying food and medicine, or dealing with emergency situations. Stores, retail stores, cafes and restaurants were closed, and remote work was recommended in all possible cases. Two weeks later, as of Sunday, 29 March, the lockdown restrictions were reinforced with a generalized closure of services, industry and construction activity. These strict measures, hereinafter referred to as "phase 2", were applied for 2 weeks and, in practice, resulted in an almost total quarantine. On 12 April, during the Easter holidays, these restrictions were lifted, reverting to the initial lockdown terms for 3 more weeks (phase 1b). On 4 May, the plan to ease the lockdown began. The so-called "de-escalation" included four phases, each of which had a minimum duration of 2 weeks. Citizens were allowed to go out for short walks, then shops and restaurants were reopened under restrictive measures, and commercial and industrial activities gradually resumed. However, face-to-face courses in schools and universities were suspended for the remainder of the 2019-2020 academic year. Finally, the state of alarm expired at midnight on Sunday, 21 June, and the country began the so-called "new normal", which includes measures such as the obligation to wear a mask in public areas or restrictions on the number of people allowed in shops and restaurants.

\section{Data and processing}

Barcelona city center is instrumented by a permanent network made up of three accelerometers managed by the Institut Cartogràfic i Geològic de Catalunya and one broadband station managed by the Geo3Bnc-CSIC institute, all of them integrated into the CA network (Institut Cartogràfic i Geològic de Catalunya, 1984). An additional accelerometer, is operational at the Fabra Observatory, located in the hills surrounding the city. The broadband instrument is a Nanometrics Trillium T120P sensor, with a flat response extended to periods of $120 \mathrm{~s}$ and using an acquisition rate of 250 samples per second (sps). The accelerometric stations are equipped with large dynamic range sensors and data loggers and acquire data at 200 sps.

The SANIMS temporary array, active from September 2019 to September 2020, consisted of six threecomponent short-period sensors (GeoSpace $2 \mathrm{~Hz}$ ) with dedicated data loggers and eight one-component Raspberry Shake seismometers equipped with $4.5 \mathrm{~Hz}$ sensors (Anthony et al., 2018). These instruments, designed primarily for "amateur seismologist" users, have proved to be useful for research projects interested in acquiring quality data and addressing outreach objectives (Plaen et al., 2020; Subedi et al., 2020). All the data acquired by the SANIMS array were transmitted in near-real time using wired ethernet connections and processed in the Geo3Bcn data center. The data acquired by the 3D seismometers can be accessed using the YS code (Diaz and Schimmel, 2019), while the data from the Raspberry Shake instruments are distributed using the AM network code (Raspberry Shake et al., 2016). The investigated zone covers an area of approximately $10 \mathrm{~km}^{2}$ within the city of Barcelona, although a couple of sites are located outside the municipality. The geometry of the network has been chosen to sample the main geological units of the Barcelona area, with sites installed in the Holocene terranes near the sea, above the Pleistocene sediments of the Barcelona plain and in the hills where Paleozoic rocks outcrops (Fig. 1). This temporary array acquires data at $100 \mathrm{sps}$, except for one of the Raspberry Shake instruments (R59E2), which uses a rate of 50 sps.

As a first processing stage, the instrumental response is removed following standard procedures and the data are displayed as seismic acceleration, expressed in $\mathrm{nm} \mathrm{s}^{-2}$. Next, the frequency content of the seismic data is analyzed using the power spectra density (PSD), which provides a good quantification of the energy levels recorded at the different frequency bands. PSD is calculated using a Obspy implementation (Krischer et al., 2015) of the classical PQLX (IRIS- PASSCAL Quick Look eXtended) software (Mcnamara et al., 2009). Data processing is based on the publicly available SeismoRMS software package (Lecocq et al., 2020b). The data are divided into 30 min windows with $50 \%$ of overlap and the PSD of each window is computed using the Welch method. Following Lecocq et al. (2020a), the default PQLX parameters have been modified slightly to improve the frequency resolution and increase the spectra dynamic. The corresponding spectrograms show the power of the seismic acceleration, expressed in decibels $(\mathrm{dB})$ referenced to $1 \mathrm{~m}^{2} \mathrm{~s}^{-4} \mathrm{~Hz}^{-1}$. To make the comparison with the spectrograms easier, the seismic-noise variations are discussed in terms of power, without converting the data to acceleration, velocity or displacement. 


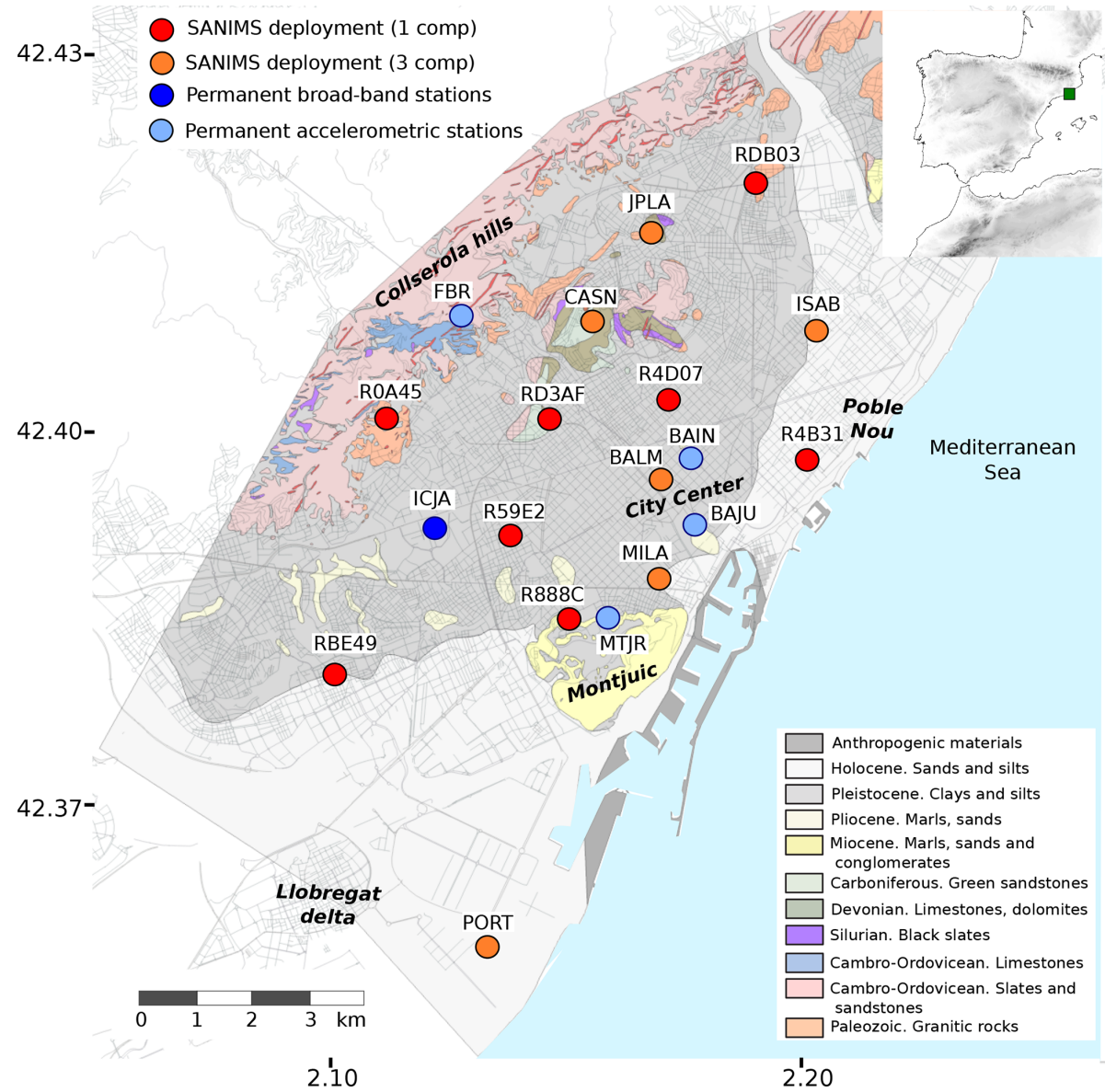

Figure 1. Location plan of the available seismic stations on the geotechnical map of Barcelona. The color code for the different types of instruments used is shown at the top-left corner. Road map from @ OpenStreetMap contributors 2020, distributed under a Creative Commons BY-SA License.

\section{Results}

\subsection{Identification of the frequency band of interest}

To analyze the effects of the COVID-19 quieting on seismic data, we must first identify the frequency range where this effect is best identified by inspecting the spectrograms at each station. Figure 2 shows the spectrograms of four representative sites for the time period beginning 3 weeks before closure and ending 3 weeks after the end of the state of alarm (24 February-12 July 2020). Supplement Fig. S1 shows the spectrograms for the 19 stations available.

Spectrograms show that human-related activity dominates above $2.0 \mathrm{~Hz}$ for most stations, confirming the previous results presented by Diaz et al. (2017). Below $1 \mathrm{~Hz}$, in the frequency range commonly known as the microseismic peak, the spectrograms show a large similarity between all the stations, as the origin of the signal is related to the interaction of oceanic waves (i.e., Díaz, 2016). The energy reduction during the lockdown period can be identified at all the stations for frequencies up to $20-25 \mathrm{~Hz}$. Although some of the sta- tions also show a significant reduction in the $35-45 \mathrm{~Hz}$ band, this is not a general feature. Therefore, we have focused our analysis on the seismic signals within $2-20 \mathrm{~Hz}$ band, calculating the averaged noise power within this band.

\subsection{Diurnal and weekly noise power variation patterns during normal activity}

Before we get into the discussion on the lockdown effects, we will review the general trends in noise variation during periods of normal activity. Figure 3 shows the time variation in the power spectra between 2 and $20 \mathrm{~Hz}$ for the 2-week interval just before the lockdown. The selected sites correspond to the ICJA broadband station, located near one of the main road accesses to the city: an accelerometer installed in the historical city center (BAJU) and two short-period stations installed in secondary schools (R888C and R4B31), one of them in an area with industrial activity.

The first observation is the clear difference between the noise power between day and night. This variation, observed systematically, has an average value close to $15 \mathrm{~dB}$, although 

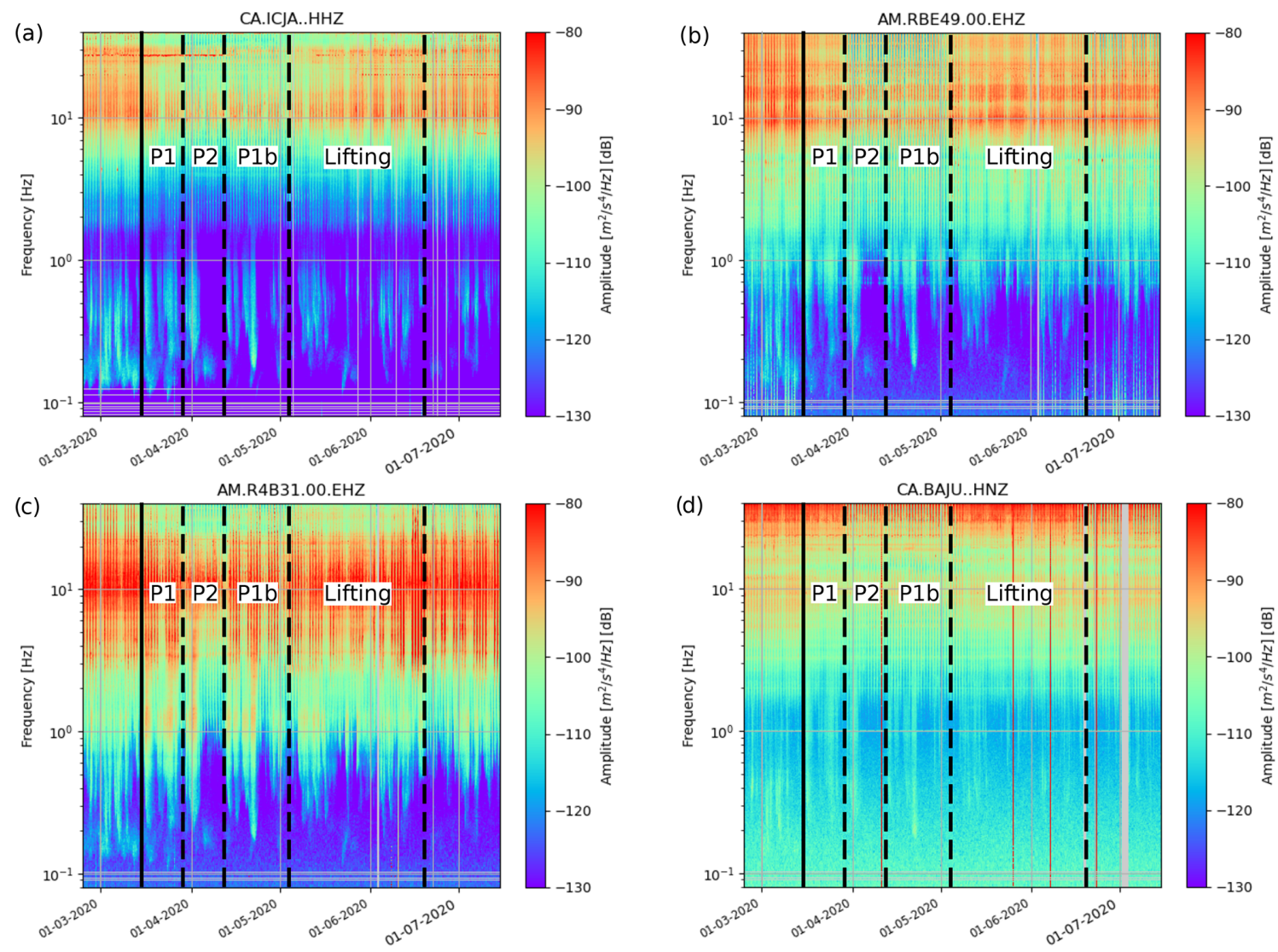

Figure 2. Spectrograms for period from 24 February to 14 July 2020 corresponding to the ICJA, RBE49, R4B31 and BAJU sites. The solid lines mark the beginning of the lockdown period and the dashed lines show the different lockdown phases in Barcelona (P1: phase 1; P2: phase 2; P1b: phase 1b). Data are expressed as $\mathrm{dB}$ relative to $1 \mathrm{~m}^{2} \mathrm{~s}^{-4} \mathrm{~Hz}^{-1}$.

some of the stations in high schools show variations greater than $20 \mathrm{~dB}$, which denotes the great influence of students' activities. High energy levels are mostly observed between 07:00 and 19:00 LT, although in some places, particularly those located near the main entrances of the city, the time interval with the highest energy begins earlier. The time interval with minimum energy is shorter, generally lasting around $5 \mathrm{~h}$, between midnight and 05:00. Typically, the maximum power during Saturdays and Sundays is around $5 \mathrm{~dB}$ lower than during working days. Most sites show an additional reduction on Sundays around 2-3 dB. Minimum levels are generally observed during Sunday through Monday nights, while power during Friday and Saturday nights is often higher than during weekday nights, reflecting more nighttime activity in the city during the weekends.

The graphs for each station display a wealth of details that reveal the activities near each site. Most sites show a fairly steep increase in noise in the morning, while the decline in the afternoon is more gradual, showing that many of the city's activities begin around 08:00, while their end times are less uniform (schools, offices and stores usually close between 16:00 and 21:00). For some of the stations in high schools (i.e., Fig. 3b) the maximum amplitudes are reached only during the morning, following the students' schedule. A remarkable example of citizen activities monitored by the variations in seismic noise can be identified at station ICJA (Fig. 3a); the two peaks observed during the afternoon of 7 March 2020 correspond to people arriving and leaving the Football Club Barcelona stadium for a Spanish league football match, played at 18:00 between FCB and Real Sociedad.

\subsection{Generic trends in power spectral variations during the COVID-19 lockdown}

As discussed in Sect. 3.1, the effect of the quieting during COVID-19 is best detected in the $2-20 \mathrm{~Hz}$ band. This effect is most marked during the more common working hours range, which can be assumed to be 09:00-19:00 in Barcelona. Therefore, we have used this frequency band and time range to calculate the daily mean values of the power spectral density. Figure 4 shows the results for all the available stations. The first 3 weeks, corresponding to the prelockdown period, are included for reference. As expected, weekends are marked by an energy minimum. The most prominent observations are as follows: (i) for most of the stations, each lockdown phase has a well-differentiated mean 
(a)
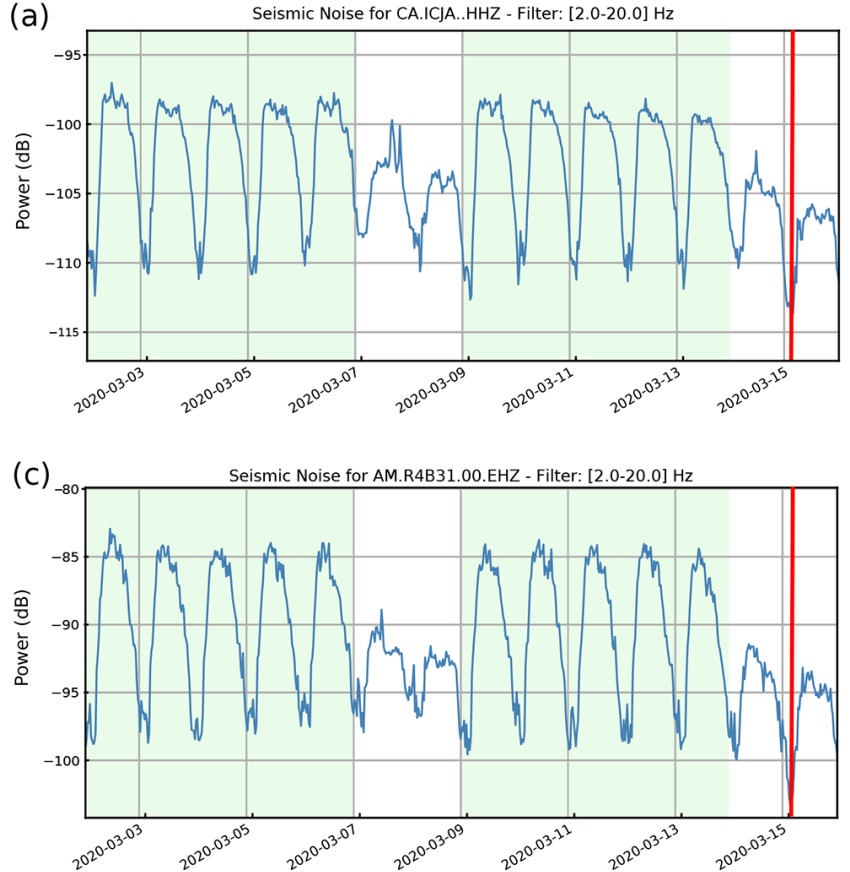

(b)

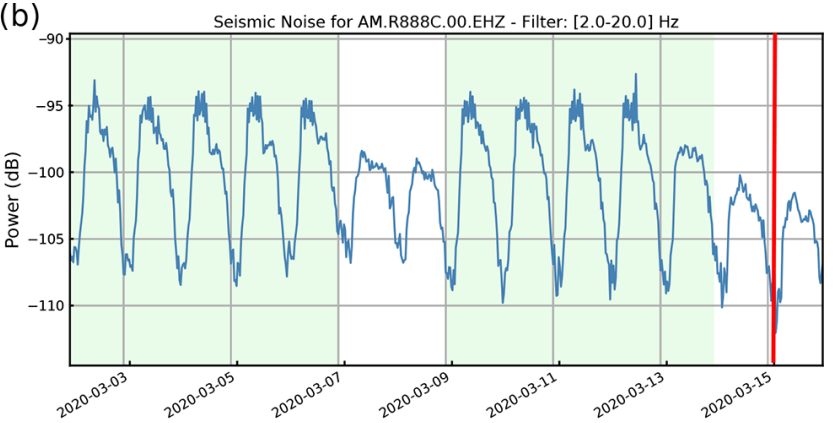

(d)

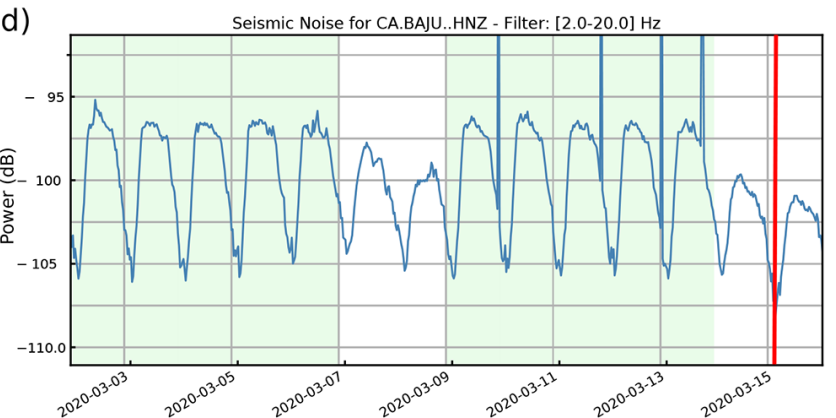

Figure 3. Trends in power acceleration variation in the $2-20 \mathrm{~Hz}$ band prior to lockdown at the ICJA (broadband), R888C, R4B31 (shortperiod stations installed in high schools) and BAJU (accelerometer located downtown). Data are expressed as dB relative to $1 \mathrm{~m}^{2} \mathrm{~s}^{-4} \mathrm{~Hz}^{-1}$. Red line marks the beginning of the lockdown period. Green shading indicates weekdays.

Table 1. Site description and differences in power amplitude observed between the different lockdown phases for all investigated seismic stations. Pre/lock1: power amplitude difference between normal period and lockdown phase 1. Pre/lock2: power amplitude difference between normal period and lockdown phase 2. Pre/new norm: power amplitude difference between normal period and "new normality" period. See text for the details.

\begin{tabular}{llrrrl}
\hline $\begin{array}{l}\text { Network } \\
\text { code }\end{array}$ & $\begin{array}{l}\text { Station } \\
\text { code }\end{array}$ & $\begin{array}{r}\text { Pre/lock1 } \\
(\mathrm{dB})\end{array}$ & $\begin{array}{r}\text { Pre/lock2 } \\
(\mathrm{dB})\end{array}$ & $\begin{array}{r}\text { Pre/new } \\
\text { norm }(\mathrm{dB})\end{array}$ & Site description \\
\hline CA & ICJA & 5 & 6 & 2 & Geo3Bcn, University area. \\
CA & MTJR & 4 & 5 & 1 & ICGC site, Montjuic Park \\
CA & BAJU & 4 & 5 & 2 & Administration building, center of town \\
CA & BAIN & 3 & 4 & 1 & Administration building, center of town \\
CA & FBR & 3 & 3 & 0 & Fabra Observatory, Collserola Hills \\
YS & BALM & 5 & 6 & 3 & Inst. Balmes high school, center of town \\
YS & JPLA & 12 & 13 & 10 & Inst. J. Pla high school (Horta) \\
YS & ISAB & 2 & 4 & 1 & Inst. Infanta Isabel high school (Sant Martí) \\
YS & CASN & - & - & - & Particular home, residential area \\
YS & MILA & 3 & 4 & 2 & Inst. Mila i Fontanals high school (Raval) \\
YS & PORT & 2 & 4 & 0 & Barcelona Port \\
AM & RDB03 & 8 & 9 & 5 & Sagrada Familia school (Sant Andreu) \\
AM & RD3AF & 3 & 4 & 2 & Inst. Montserrat high school (Sant Gervasi) \\
AM & RBE49 & 5 & 6 & 2 & Tecla Sala school (Hospitalet Llobregat) \\
AM & R888C & 6 & 6 & 3 & Inst. XXV Olimpiada high school, near Montjuic Park \\
AM & R59E2 & 4 & 4 & 2 & Maristes Les Corts high school (Sants) \\
AM & R4D07 & 5 & 6 & 2 & Inst. La Sedeta high school (Eixample) \\
AM & R4B31 & 3 & 6 & 0 & Voramar school (Poble Nou) \\
AM & R0A45 & 17 & 18 & 5 & Inst. Costa i Llobera high school (Collserola) \\
\hline
\end{tabular}


amplitude value; (ii) there are large variations in amplitude between sites; (iii) the details of the amplitude changes differ significantly between groups of stations.

Most of the stations have maximum values around $-90 /-95 \mathrm{~dB}$. However, a couple of stations (PORT, R4B31) are much louder, with reference values between -80 and $-90 \mathrm{~dB}$. On the other hand, some of the sites within the city (JPLA, RD3AF, CASN) have low values around $-105 /-$ $110 \mathrm{~dB}$. The minimum values are observed for FBR, a station located in the Collserola Hills that surround Barcelona, outside the city and relatively far from roads and train tracks, and R0A45, installed in a high school within the city but near the Collserola Hills.

To obtain a global picture of the noise power variations in the city, we have calculated an average power amplitude profile for the entire network. The profiles obtained for each station (Fig. 4) have been normalized to the $0-1$ range and the results averaged to obtain a mean profile (Fig. 5) that can be regarded as a summary of the results discussed in this contribution.

Despite the large differences in values between the sites, these normalized profiles show that the temporal evolution of the background vibration in the $2-20 \mathrm{~Hz}$ band is consistent for most of the sites. During phase 1, the mean power level gradually decreases to reach a minimum during the 2 -week period of maximum restrictions (phase 2) and then increases smoothly until mid-July, without reaching pre-lockdown values. The reduction is also clearly shown during the weekends (minimum values in Fig. 5) and in the difference between weekdays and weekends, which is minimal during the second week of phase 2.

To take advantage of the large number of stations available, we have represented the same information as daily maps. The normalized values are located on a city map, gridded using a nearest-neighbor algorithm and presented as Supplement Fig. S2. Figure 6 summarizes the information showing the images of four Mondays, each corresponding to one of the lockdown phases. Although the maps may include some spurious effects due to the interpolation procedure, they provide visual information on the variation in the seismic power, denoting clearly differentiated pre-lockdown, lockdown phases 1 and 2, and lifting periods. In pre-lockdown times, most of the stations have their highest absolute values, thus appearing in the maps with normalized values close to 1 (Fig. 6a). During lockdown phases 1 and $1 \mathrm{~b}$ most of the sites remain below average, except for a couple that are affected by local sources of noise that will be discussed in the next section (Fig. 6b). During the weeks with stricter lockdown measures (Fig. 6c) all stations have the lowest power and the normalized values are close to zero. During the lifting period (Fig. 6d) the sites progressively increase in amplitude. Note that weekends and holidays (13 April, 1 May, 1 and 24 June) are identified in the daily snapshots by their low power levels (Fig. S2).

\subsection{Site-dependent characteristics of power variations during the COVID-19 lockdown}

The relatively large number of sites within Barcelona makes it possible to analyze in detail the variations in power and to study the influence of very local noise sources, which can eventually distort the interpretation of the results. Figure 7 shows the power amplitude in the $2-20 \mathrm{~Hz}$ band measured every $15 \mathrm{~min}$ (light blue line) and the daily mean value during business hours (dark blue line) for some selected sites. Supplement Fig. S3 presents the same information for all the sites. In these figures, the light blue lines show the power amplitude evaluated every $15 \mathrm{~min}$ and the dark blue ones show the daily average value during business hours (09:0019:00 LT). The orange lines show the mean value of the business hour amplitudes for an interval of 1 week, smoothing out the weekend lows and facilitating the discussion of the long-term variations.

During working hours, the drop in noise power following the onset of the quieting measures has a mean value of $4 \mathrm{~dB}$ for phase 1 of lockdown (Table 1). The reduction is more prominent for those sites located in schools (BALM, JPLA, ISAB, MILA, RDB03, RD3AF, RBE49, R888C, R59E2, R4B31, R0A45), reaching in some cases values of up to $17 \mathrm{~dB}$. This large reduction reveals the impact of very close sources of vibration (in this case, the movement of students in school) on the seismic data. During the stricter phase 2 lockdown period, one additional $\mathrm{dB}$ of reduction is observed for most of the sites, although in a couple of cases the decrease is greater. The reduction also affects periods with low levels, such as the weekends (lows in the dark blue lines) or night periods (lows in the light blue lines). During lockdown, the difference in energy levels between weekdays and weekends is also drastically reduced. While in the days before lockdown this difference is around $5 \mathrm{~dB}$, at the peak of the quieting it remains between 2 and $3 \mathrm{~dB}$. As discussed above, most of the stations share a fairly similar pattern of variation, but some of them have clearly different results. Figure 7 displays the variation in power for several sites showing the general variation trend (Fig. 7a-d) and for most of the sites where particular characteristics have been identified (Fig. 7e-h).

The ICJA station (Fig. 7a) is installed in the basement of the Geo3Bcn institute, located within a university campus and near one of the main roads into the city. Díaz et al. (2017) have documented a close relationship between seismic noise around $10 \mathrm{~Hz}$ and the traffic entering and exiting from the city. The changes in seismic power are smooth, with a progressive decrease during the first 2 weeks and a clear minimum during the phase 2 lockdown. During phase $1 \mathrm{~b}$, the increase is constant and continues during the period of lifting. Station RBE49 (Fig. 7b) is located in the Tecla Sala school, in the center of Hospitalet de Llobregat, an independent city forming a continuous urban environment with Barcelona. As with all stations located in schools, student activity is a major source of vibrations around $10 \mathrm{~Hz}$. This is evidenced here 


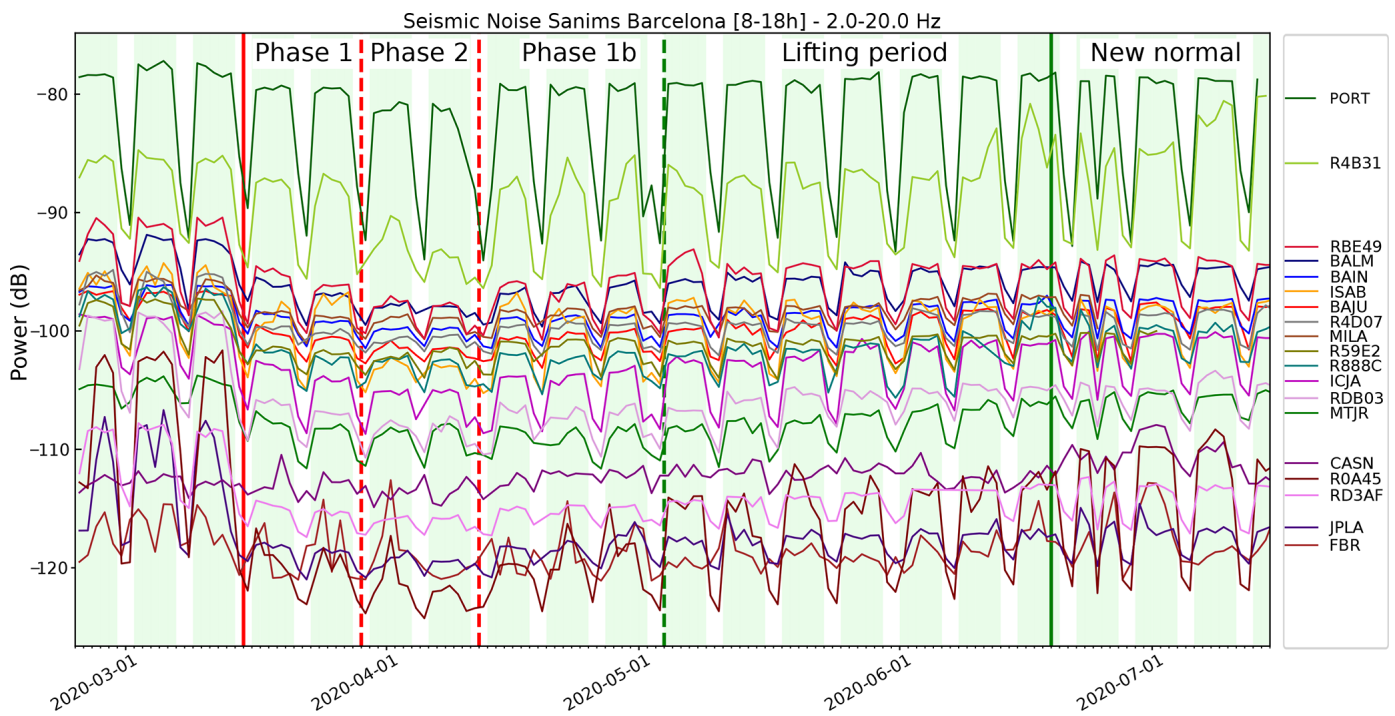

Figure 4. Variation in the power of the seismic acceleration in the $2-20 \mathrm{~Hz}$ band for all the investigated sites, expressed in dB. The colored lines show the daily average during business hours. The vertical bars show the start dates of the phase 1 lockdown period (solid red bar), the period with stricter measures (phase 2, dashed red lines) and the beginning of the lifting period (dashed green line) and the so-called "new normal" (solid green line). Light green shadings show weekdays.

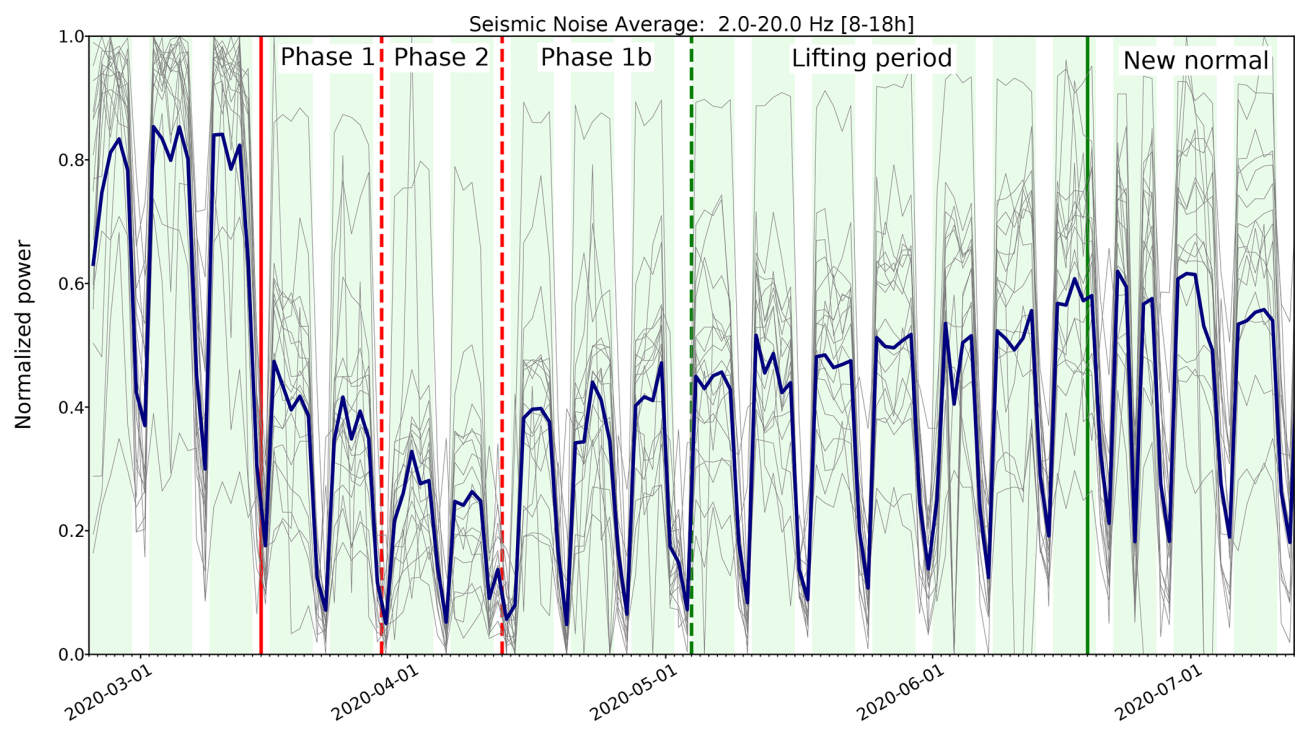

Figure 5. Normalized power in the $2-20 \mathrm{~Hz}$ band during working hours for all the stations (gray lines) and the corresponding mean profile (blue line). Bars as in Fig. 4.

by the lower noise observed on Friday, 13 March, just before the start of the lockdown, when schools were already closed. The pattern is similar to that of ICJA, although a particular increase can be observed during the first week after the start of the release measures. Face-to-face classes did not restart in Barcelona until September 2020, but the increase probably reflects the activity of the school to prepare online courses and materials. The BALM seismometer (Fig. 7c) is also installed in a high school, located in this case in the center of Barcelona, in the Eixample neighborhood and close to monuments such as Casa Batlló and Casa Milà. The seismic results here show a greater difference between lockdown phases 1 and 2, suggesting that the effect of strict closure was more effective in the city center. The last example of sites that register quite similar noise variations is BAJU (Fig. 7d), an accelerometer located in an administrative building in the historical center of the city, near shopping centers and tourist attractions. The results are consistent with previously mentioned examples, although some specificities can be highlighted. For example, the noise level is not stable during the 
(a)

(c)
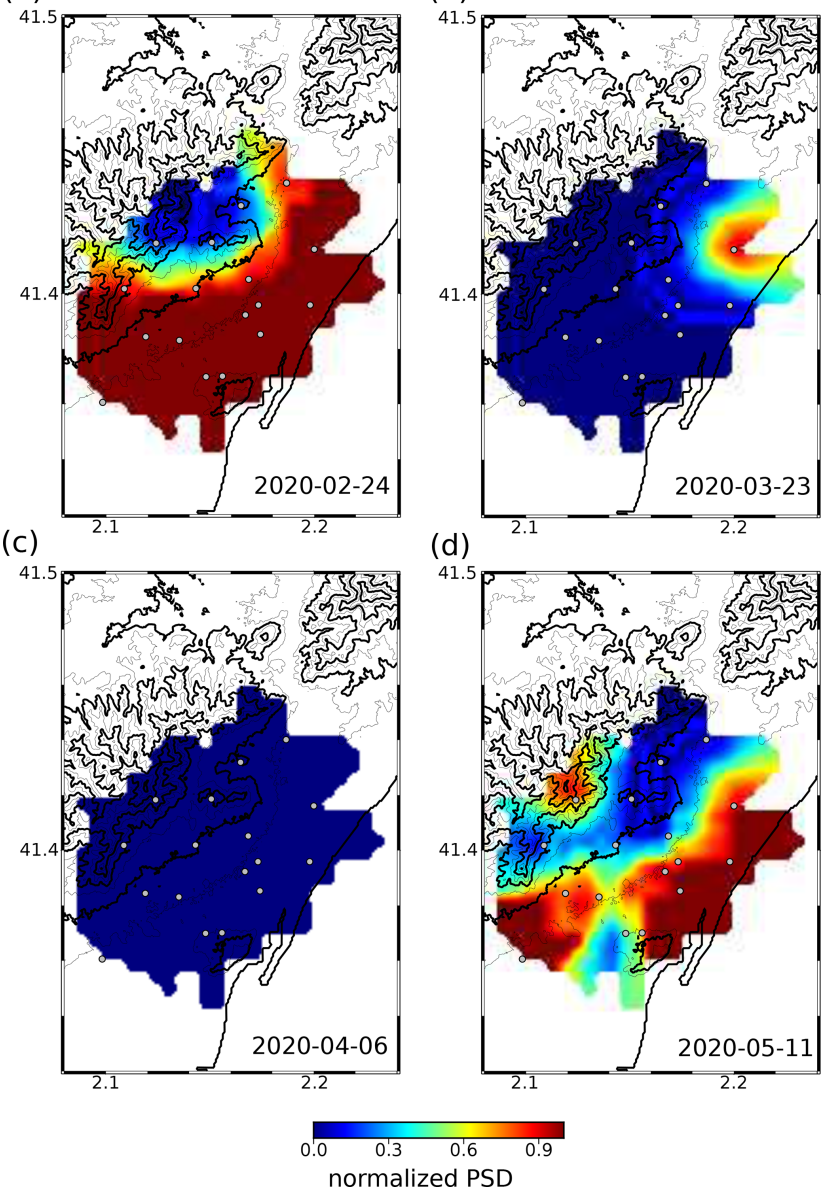

Figure 6. Daily maps representing the normalized power in the 2$20 \mathrm{~Hz}$ band during working hours. Each image corresponds to a Monday (Fig. S2 shows all the daily snapshots). (a) Pre-lockdown period. (b) Lockdown phase 1. (c) Lockdown phase 2. (d) Lifting period. Topographic contours are included for reference (thick lines: $100 \mathrm{~m}$ interval; thin lines: $50 \mathrm{~m}$ interval).

2 weeks of the phase 2 period, with the second one clearly being quieter. Also note that the difference between weekdays and weekends and between day and night appears to be smaller than for the previous cases.

If we focus on stations having abnormal results, we can first comment on the results of station R4B31, located in the Voramar school in the Poble Nou neighborhood, in an area of old wetlands and swamps close to the beach (Fig. 7e). The noise reduction during the lockdown phase 1 is modest, despite the fact that students were staying at home. The only time period with a large noise reduction is during lockdown phase 2 and, in particular, during the second week of this phase. Also note that during phase $1 \mathrm{~b}$ and during the period when the measures were lifted the power reaches values that are very similar to those of the pre-lockdown period, contrary to what is observed in most sites. To understand these results, we visited the area and noticed that a historical industrial factory, Industries Waldes is located right in front of the school. This factory, still in full activity, is specialized in the production of buttons, snaps, metal fittings and other metal accessories and uses heavy machinery (https://waldes.es/en/company/, last access: 19 March 2021). Following the government's guidelines, industry only closed during phase 2 of the lockdown, explaining the reduction in seismic noise during this period. Noise levels are also abnormally high in mid-June and mid-July, during a period with almost normal levels of urban activity. This seems to be related to the activity at a large construction site located about $150 \mathrm{~m}$ from the sensor. Station PORT, located next to one on the main container terminal in the port of Barcelona and approximately $1 \mathrm{~km}$ away from one of the largest water treatment plants in Europe (https://www.amb.cat/ en/web/ecologia/aigua/instalacions-i-equipaments/detall/ -/equipament/edar-del-prat-de-llobregat/276285/11818, last access: 19 March 2021), seems also to be dominated by nearby sources of noise related to industrial activities, resulting is a noise reduction limited to the 2 weeks of total closure of activity (Fig. S3). The results for these sites show that vibration sources located near the seismic sensor can dominate the signal and disturb the interpretation of the data in terms of general human activity. Station CASN (Fig. 7f) was installed in the basement of a private house located in the Paleozoic hills near Park Güell, relatively far from large avenues and industrial areas. In this case, the seismic noise does not reproduce the lockdown quieting clearly, although the weekly mean value (orange line) shows a small decrease during phases 1 and 2 and a slight but constant increase thereafter. The sharp change observed at most sites is not observed here. We think that the increase in the vibrations generated by the family members, usually working or studying at other places but staying at home since the beginning of the lockdown, compensates for the general decrease in seismic noise, thus masking the change related to the start of lockdown. It can be noted that similar observations are been reported in social media by users of the Raspberry Shake citizen seismic network. Figure $7 \mathrm{~g}$ shows the results of the Inst. Josep Pla high school, located in the Horta neighborhood. Here, contrary to the situation described for R4B31, the influence of students on seismic noise is enormous, as reflected in the very sharp decrease as of Friday, 13 March. The noise level during business hours decreases by more than $12 \mathrm{~dB}$ and remains $10 \mathrm{~dB}$ below the usual values until the end of the investigated time period. This is interpreted as being due to the quiet environment around the site, away from large avenues and industry axes and next to a medium-sized urban park. Finally, the data acquired at the FBR station (Fig. 7h), located in the hills outside the city, shows that, although a decrease in the weekly averages can be observed following the beginning of lockdown, the variations in power follow a clearly different pattern than for most of the sites. The spectrogram for this station (Fig. S1) shows that the seismic-noise variation in the 
(a)

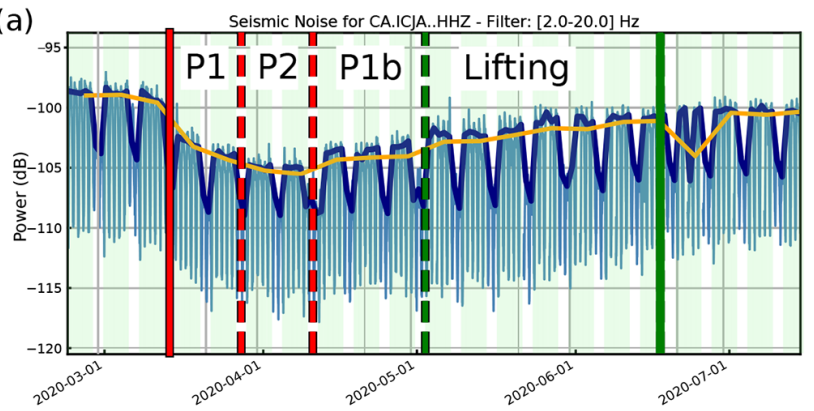

(c)

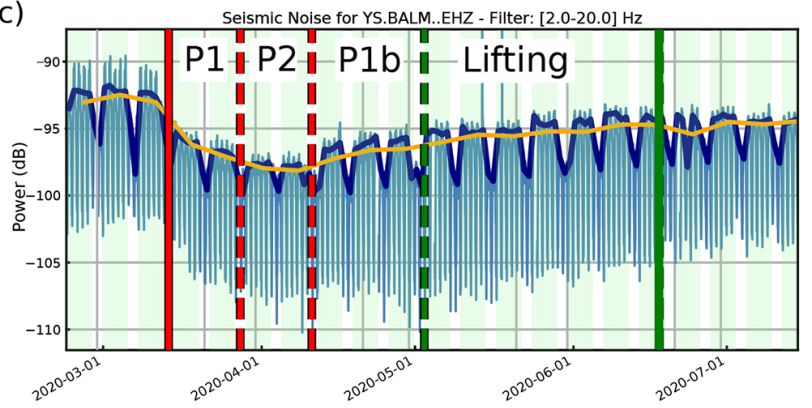

(e)

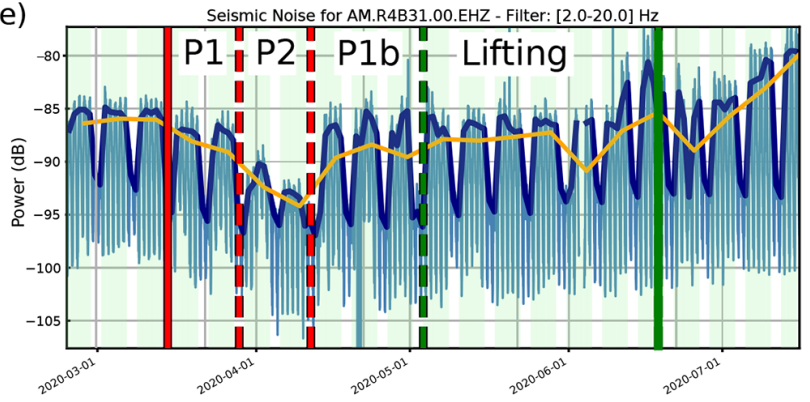

(g)

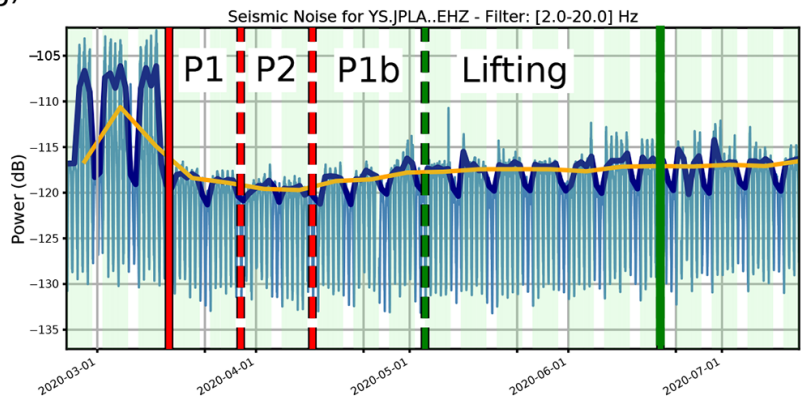

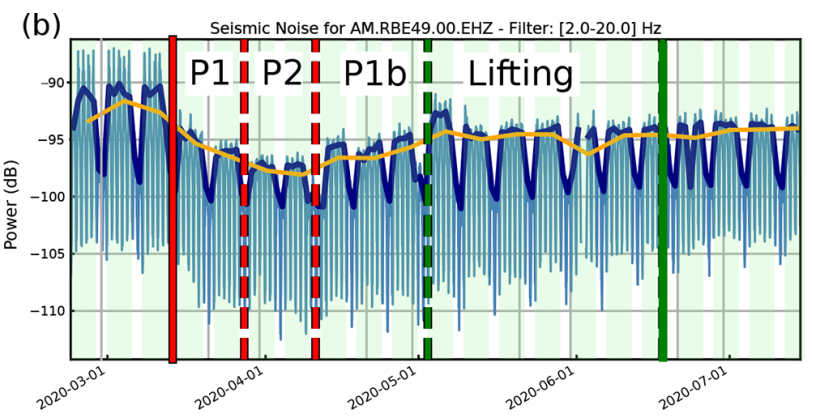

(d) Seismic Noise for CA.BA]U..HNZ - Filter: [2.0-20.0] Hz

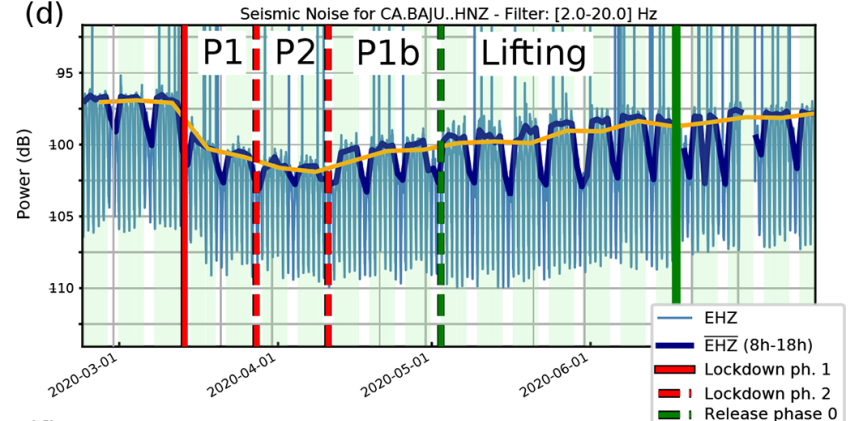

(f) Seismic Noise for YS.CASN..EHZ - Filter: [2.0-20.0] H I Release phase

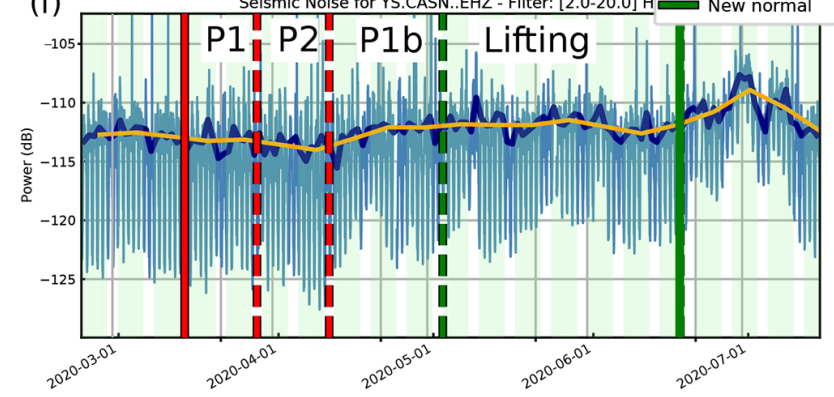

(h)

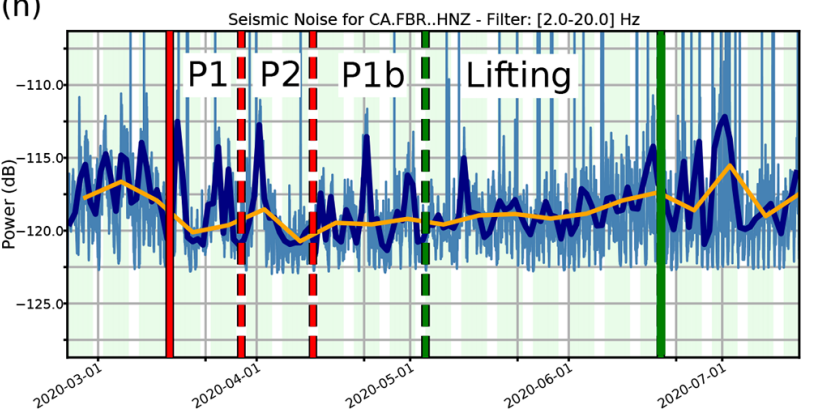

Figure 7. Variations in the PSD of the seismic acceleration in the $2-20 \mathrm{~Hz}$ band for representative stations. (a-d) Sites that follow the general trend. (e-h) Sites with particular characteristics (see text). Light blue line: data every $15 \mathrm{~min}$. Dark blue line: daily mean value during business hours (09:00-19:00). Orange line: weekly mean average during working hours.

$2-20 \mathrm{~Hz}$ band is very similar to that observed for frequencies below $1 \mathrm{~Hz}$, a range for which wind and oceanic waves are widely acknowledged to be that the dominant sources of noise (i.e., Díaz, 2016). Therefore, we conclude that for this station, with low levels of human activity nearby, the lower-frequency seismic sources extend to the $2-20 \mathrm{~Hz}$ band.
To better discuss the differences between the different stations, we have mapped the absolute power values in the 2$20 \mathrm{~Hz}$ range, following the same approach discussed previously for the normalized data. Figure S4 show all the snapshots, while Fig. 8 shows the images corresponding to four Mondays at different lockdown phases. During the prelockdown period (Fig. 8a) there is a rough correlation between the seismic noise and the geologic zonation, with 
lower noise for stations located in Precambrian hills and higher levels in the sites located in the recent Quaternary sediments. This correlation between geology and seismic amplification is a well-known feature that has been documented at the scale of the Iberian Peninsula, where high seismic noise is observed over sedimentary basins and minimum values are found over hard-rock regions (Custódio et al., 2014; Díaz et al., 2010). However, in an urban environment such as Barcelona, this relationship has to be treated with caution, as the Quaternary areas include most of the city center, the area most affected by human activity. After the beginning of the restrictive measures (Fig. 8b), the noise distribution changes slightly, with the area with low noise levels extending towards the city center. The reddish spot near the coast corresponds to station R4B31, affected by an industrial factory located nearby and located over the most recent Holocene sediments. During the stricter lockdown interval (Fig. 8c) the activity at this factory was suppressed, and this is reflected in the seismic-noise maps, which can be more directly related to geology. Figure $8 \mathrm{~b}$ and $\mathrm{c}$ show that during the lockdown phase, the Miocene areas around Montjuic have lower amplification than the zone covered by Quaternary sediments, a feature not observed in normal times. During the lifting period (Fig. 8d) the vibrations affecting R4B31 reappear and noise levels progressively recover, although without reaching the pre-lockdown levels. The area with lowest noise progressively reduces, although it remains larger than in prelockdown times. The snapshots in Fig. S4 also show the amplitude decrease during weekends and holidays.

Therefore, during lockdown phase 2, with minimal human activity, the geographical variations in seismic energy are mostly due to the amplification factor related to the subsoil geology, and the maps are highly consistent with the microzonation map proposed by Cid et al. (2001) and with the results based on the analysis of fundamental resonance frequency using the horizontal to vertical spectral ratio (HVSR) by Cadet et al. (2011). This direct relationship is less clear during normal human activity periods, as industries and traffic close to each station strongly disturb the seismic power.

\subsection{Long-term noise power variations}

To put the decrease in seismic noise into perspective, we have calculated the power variation since January 2019 for three permanent seismic stations located within Barcelona: the ICJA broadband station and the BAIN and BAJU accelerometers (Fig. 9). As for Fig. 7, light blue lines show data every $15 \mathrm{~min}$, dark blue lines represent the average during working hours and orange lines show the weekly average during working hours. In this case, the data in the figure extend until the 30 September 2020. The spikes often observed for the BAIN and BAJU sites are related to data transmission problems and are not relevant for the discussion.

All three sites show a similar pattern, although small differences can be identified. During the Easter holidays of (a)

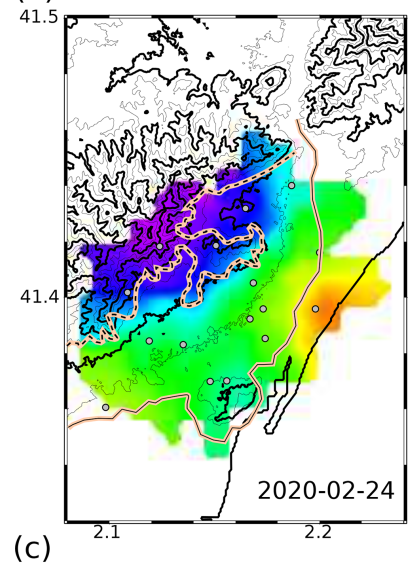

41.5

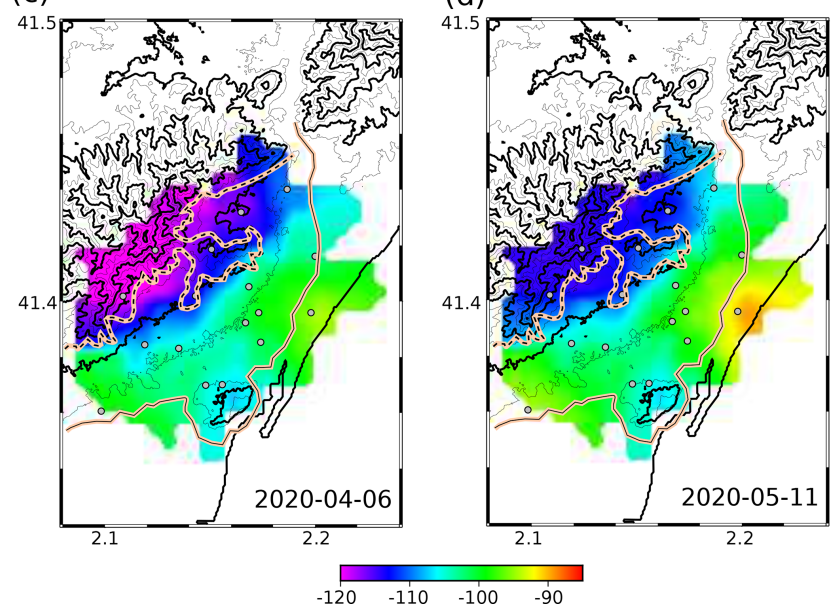

Figure 8. Daily maps representing the real power values in the $2-$ $20 \mathrm{~Hz}$ band during working hours. Each image corresponds to a Monday (Fig. S4 shows all the daily snapshots). (a) Pre-lockdown period. (b) Lockdown phase 1. (c) Lockdown phase 2. (d) Lifting period. The dashed line marks the limit of the Paleozoic materials in the hills that surround Barcelona. The solid line marks the boundary between the areas covered by Holocene and Pleistocene materials (see Fig. 1).

2019, the average weekly noise decreases for all the sites, but this is particularly visible at the ICJA station, where the decrease reaches $4 \mathrm{~dB}$. The 2019 summer holidays are clearly identified in the seismic data by a decrease throughout the month of August, the traditional period of holidays in Spain. This quieting is a little less marked than during the Easter holidays but it lasts for a period of 4 weeks. During both holiday periods, BAJU shows a less prominent decrease than the other stations. This site is located in a tourist area of the city center, and we can hypothesize that the increase in tourist activity during the holidays can offset the decrease in the activity of local citizens. The 2019 Christmas period is also well reflected in the seismic data, with a decline lasting about 2 weeks and reaching similar values as those during the Easter holidays. A significant increase is observed at BAJU at the beginning of November 2019. This increase, only ob- 

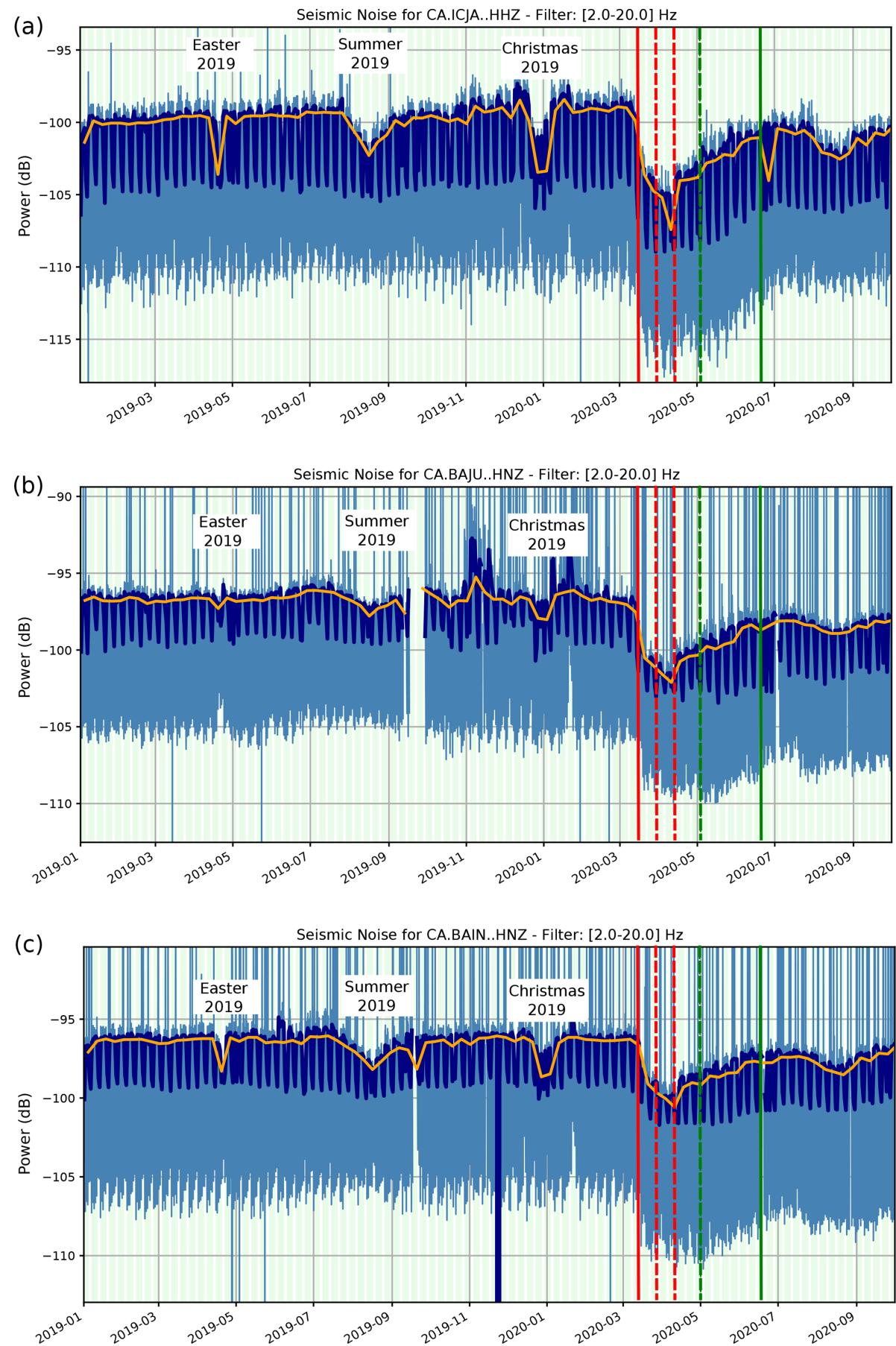

Figure 9. Long-term (1 January 2019-30 September 2020) PSD of the seismic accelerations in the 2-20 Hz band. (a) ICJA broadband seismometer. (b) BAJU accelerometer. (c) BAIN accelerometer. Color code as in Fig. 7.

served for this site, remains unexplained due to a lack of local site information.

As clearly shown in the data presented in Fig. 9, the effects of the COVID-19 lockdown have a much greater impact in the seismic power of the $2-20 \mathrm{~Hz}$ band than the usual holiday seasons. During lockdown phase 1 the decrease is only slightly greater than during the holidays, but during the
2 weeks with stricter closure, the maximum noise levels during business hours are clearly below the levels observed during the holidays and weekends. As mentioned early, during the release period, the power increases smoothly but does not reach the pre-lockdown levels. During 2020, the Easter holidays were coincident with the lockdown period and could not be clearly identified in the data. By contrast, even in the 
context of limited citizen activity, the August holidays have a clear impact in the seismic-noise levels.

\section{Seismic data and mobility patterns}

From the data analyzed in the previous sections, it is clear that seismic power in the $2-20 \mathrm{~Hz}$ band can be used as a proxy to monitor the level of anthropogenic activity in an urban environment. Verifying mobility patterns during lockdown periods is an important tool to analyze the efficacy of the different lockdown strategies adopted by civil authorities. The exceptionality of this period has led several large companies such as Google, Apple or Facebook to agree to make their mobility data public for a limited period. Similarly, the main mobile phone operators have shared data related to the mobility of the devices under their control with government agencies. Other mobility indicators can be the number of ticket validations in public transportation systems and the estimations of vehicle movements in the city, obtained from vehicle counters installed in representative locations. In order to evaluate the real usefulness of seismic data to be used as a monitoring tool, we have compared our results with some of these indicators.

Some of the indicators provided by large communication companies as Google or Apple are shown in Fig. 10a together with the averaged seismic data. The indicators are normalized to the 0-1 range to make a visual comparison possible. The black line shows the data provided by Apple (https: //covid19.apple.com/mobility, last access: 19 March 2021) regarding the relative number of address requests on Apple Maps from people driving vehicles around the Barcelona area, compared to 13 January 2020 (Monday). Apple data show a sharp decline during the first week of phase 1 and remain fairly stable until the beginning of phase $1 \mathrm{~b}$. During phase $1 \mathrm{~b}$ and the lifting period, the indicator increases at an increasing rate. In mid-July, the indicator returned to prelockdown levels. The green line in Fig. 10a shows the change in activity in places related to public transportation such as metro, bus and train stations, as provided by Google for the Barcelona area (https://www.google.com/covid19/mobility/, last access: 19 March 2021). These data refer to the median value for the same day of the week during January 2020 and hence do not show the weekday-weekend variation. During lockdown phases 1, 2 and $1 \mathrm{~b}$, the pattern is similar to Apple's data. However, during the first weeks of the lifting period, the increase is more marked. In contrast, during the new normal period, the indicator remains fairly constant. Turning now to the datasets made available through public institutions, we have first analyzed the data provided by the Barcelona transportation authority (https://www.atm. cat/web/ca/covid19.php, last access: 19 March 2021) regarding the number of validations of trips in public transportation systems within the city, including bus, metro and tramway (blue line in Fig. 10b). This dataset is not based on mobile phone activity but comes directly from transportation operators. The absolute number of daily validations ranges from a low of 72797 on 12 April, during the second week of phase 2 lockdown to 1893739 on 9 July. As in previous cases, the use of public transportation begins to increase during phase $1 \mathrm{~b}$, but in this case the data show a very constant rate, both on weekdays and on weekends, until mid-July. Finally, we have inspected the data provided by the Spanish Institute of Statistics (INE, https://www.ine.es/covid/tabla.htm, last access: 19 March 2021) on the mobility at the scale of the small zones, chosen to include around 20000 inhabitants each (in the case of Barcelona, the this means more than 70 zones). The data are based on the information provided by the three main mobile phone operators in Spain on the location of mobile phone devices and show the percentage of the population moving from their home during each day as referenced to the value between the 18 and 21 November 2019 (Monday to Thursday). Only the data corresponding to the lockdown period have been opened. We have calculated the mean values of these data for all the mobility areas of Barcelona and represented them as a green line in Fig. 10b, normalized to the $0-1$ range.

As expected, the overall correlation between the different indicators is good, all of them highlighting the decrease in activity during the lockdown period. However, some significant differences can be observed between them. The seismic data clearly show the decrease in activity during phase 1 and phase 2, with the minimum level observed during the second week of phase 2. During phase $1 \mathrm{~b}$, the average seismic amplitude quickly recovers the levels of phase 1 , a fact that is also observed in the INE mobility data and in the number of public transportation validations (Fig. 10b) but not so clearly in the data from Apple and Google. The main differences between the different indicators appear during the end of the release phase and the beginning of the new normal period. Public transportation validations increase at a fairly constant rate from the end of March to mid-July, while Google's public transportation estimations show a marked increase at the beginning of phase $1 \mathrm{~b}$ and stabilize from the end of June. When comparing the INE mobility estimations and Apple's estimate for driving activity, significant differences can be identified, for example, in the relative amplitude during weekdays and weekends. Apple's data for July have a maximum value on Friday that does not appear in other indicators, such as the volume of traffic in and around the city. Therefore, each indicator has its own peculiarities and none of them can be regarded as a ground-truth reference.

The most relevant difference between the seismic data and other indicators is the fact that seismic power has remained almost stable since the end of May and has not recovered its pre-lockdown level, while the other indicators continue to increase during June and July until they recover their levels. This fact can be understood by assuming that seismic noise arises from two main sources: traffic and movement in the vicinity of the sensor, normally due to the activity of peo- 

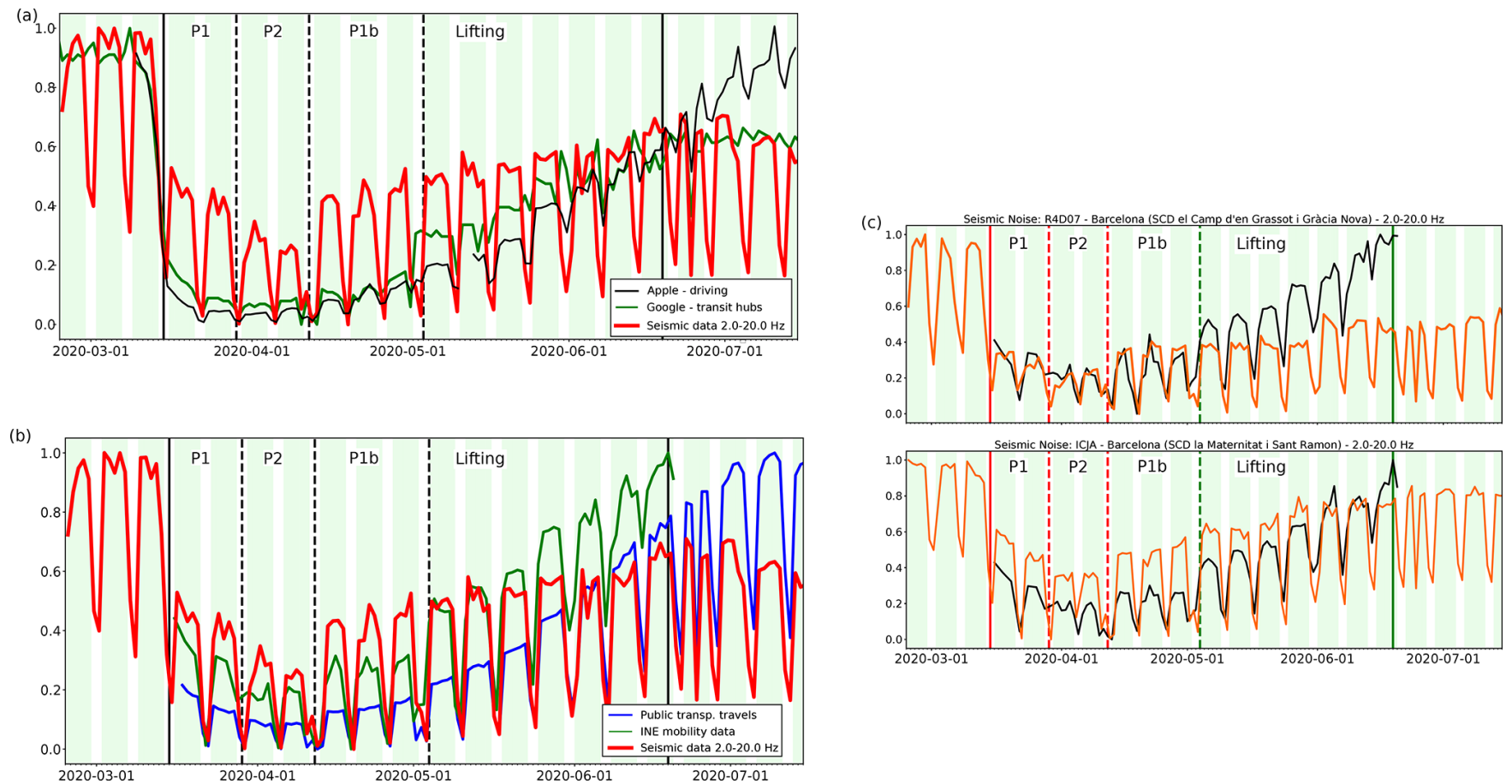

Figure 10. Mobility data from different sources compared to seismic data. (a) Normalized mean seismic power during business hours (09:0019:00) vs. mobility data from Apple and Google. (b) Normalized mean seismic power during business hours vs. the number of validations of public transportation and the INE mobility data averaged for the Barcelona area. (c) Normalized power (orange line) during business hours for stations R4D07 (upper panel) and ICJA (lower panel) and INE mobility data for the corresponding mobility zones (black lines).

ple in the building, such as students in high school or workers in the office. This hypothesis is confirmed by comparing the seismic-noise level at each site with the INE data for each mobility zone. Figure 10c shows two clearly different cases. Station R4D07, located in a secondary school near Sagrada Familia, shows a good match between mobility and seismic data during phases 1,2 and $1 \mathrm{~b}$, but afterwards mobility continues to increase while seismicity remains stable. On the other hand, in the ICJA station the seismic and mobility indicators have a more similar evolution, although the difference between weekdays and weekends is greater for the seismic data during the lockdown period. This site is located near one of the main access roads into Barcelona, a fact that may explain the greater relative contribution of traffic. From these observations, we conclude that background seismic vibrations in the $2-20 \mathrm{~Hz}$ band are related to the traffic volume only up to a certain threshold, above which further increases in traffic do not affect the seismic data. The second main source of vibrations in this band is related to human activity near the seismometer. The daily variations in seismic amplitude in this frequency band does not correlate with the subway schedule during the pandemic, which confirms previous contributions where it was stated that the subway transportation system produces vibrations at frequencies ranging mostly between 20 and $40 \mathrm{~Hz}$ (Díaz et al., 2017; Green et al., 2017; Hinzen, 2014).

\section{Conclusions}

As a summary, we can conclude that seismic data in the 2$20 \mathrm{~Hz}$ band are a good proxy of the local anthropogenic activity. The effects of the lockdown measures taken after the outbreak of the COVID-19 pandemic are clearly seen at most sites, as previously documented at a worldwide scale (i.e., Lecocq et al., 2020a). The variations in seismic power over time make it possible to distinguish between the different phases of lockdown, at least in a similar way to other mobility indicators. Comparing this with previous data acquired by the permanent seismic stations in Barcelona, we can conclude that the quieting during lockdown is clearly higher than the noise lowering observed during holiday periods. Having a dense seismic network deployed over the city has provided the opportunity to analyze in detail the effects of the lockdown measures on the 19 available sites, showing that the mean results accurately reproduce the human activity pattern but also that significantly different results are obtained for some sites, where nearby and specific noise sources dominate the recorded signal. Seismic noise between 2 and $20 \mathrm{~Hz}$ is mostly sensitive to traffic, industrial and construction activities at distances of a few hundred meters and can hence be regarded as a proxy to monitor these human activities. Our results suggest that above a certain threshold, the increase in traffic is no longer reflected in the seismic data. This thresh- 
old value is probably related to the distance between the seismometer and the source area and to the attenuation properties of the subsoil. Compared to other mobility indicators, seismic data have some important advantages; the data are open and their availability does not depend on the decisions of private companies; traffic and industrial activities are aggregated; the installation and maintenance of the sensors is easy; and there are well-established protocols to share the data in near-real time. This opens the door to the systematic use of seismic sensors as tools to monitor human activity in urban areas. This monitoring can be crucial in times of crisis that involve changes in the usual mobility patterns, but it can also be of practical use in regular times.

We also want to highlight the value of operating an urban seismic network for the dissemination of Earth sciences, in particular if some of the stations are installed in secondary schools. Having these instruments available in the classroom is a great opportunity to develop students' interest not only in seismology or Earth sciences, but also, more generally, to promote the use of scientific methodologies. Collaboration with educational centers has led to three high school research projects based on the analysis of seismic data, despite the scarce presence of Earth sciences in Spanish curricula. Seismic records in urban environments also provide an opportunity to access the media and have a significant impact on social networks; the COVID-19 lockdown has been an extraordinary opportunity in this regard, but even at regular times, the detection of sporting or musical events, extreme weather phenomena, controlled explosions, disturbances in the public transportation system, etc., can be of interest to a public unfamiliar with Earth sciences.

Code availability. This work has benefited from open-source initiatives such as Obspy (Krischer et al., 2015) and GMT (Wessel et al., 2013). Data analysis has been done using the publicly available SeismoRMS code kindly distributed by Thomas Lecocq (Lecocq et al., 2020b).

Data availability. The seismic data acquired by the CA network can be found in the Institut Cartográfic i Geológic de Catalunya repository (Institut Cartogràfic i Geològic de Catalunya, 1984). Seismic data for the AM network can be found in the Raspberry Shake repository (Raspberry Shake et al., 2016). Data from the YS stations will be available from the ORFEUS Data Center are available on request from the corresponding author and will be distributed publicly at the end of the embargo period.

Supplement. The supplement related to this article is available online at: https://doi.org/10.5194/se-12-725-2021-supplement.
Author contributions. JD, MR and JAJ worked on the data acquisition, processing and analysis. JD wrote the paper and prepared the figures, with contributions from all co-authors.

Competing interests. The authors declare that they have no conflict of interest.

Special issue statement. This article is part of the special issue "Social seismology - the effect of COVID-19 lockdown measures on seismology". It is not associated with a conference.

Acknowledgements. We acknowledge the Geo3Bcn-CSIC LabSis Laboratory (http://labsis.geo3bcn.csic.es, last access: 19 March 2021) for making their seismic station available for this experiment. We want to thank the secondary school teachers involved in this research project for their collaboration and help: Xavier Valbuena (Escola Tecla Sala), Antoni Cirera (Inst. Costa Llobera), Nuria Prat, Olaia Iglesias (Inst. Balmes), Xavier Pie, Fina Brull (Inst. Infanta Isabel d'Aragó), Miguel Manzano (Inst. Montserrat), Gemma Briones (Escola Voramar), Oscar Arribas (Inst. Milà i Fontanals), Robert Barriche (Escola Sagrada Familia, Sant Andreu), Angel Domingo (Maristes Sants-Les Corts), Elisa Rodriguez (Inst. Josep Pla), Angel Mota, Omar Marín (Inst. La Sedeta) and Carles Sanchiz (Inst. XXV Olimpiada). We also want to thank Dani Ruiz, Jordi Vila and Joaquim Cortés, from the Dep. de Medi Ambient of the Port de Barcelona for facilitating the installation of one of the sites. Finally, we thank the National Institute of Statistics (INE) and the Autoritat del Transport Metropolità de l'àrea de Barcelona (ATM) for sharing detailed mobility data.

Financial support. This research has been supported by the Ministerio de Ciencia, Innovación y Universidades (grant no. RTI2018-095594-B-I00), and the Generalitat de Catalunya (grant no. 2017SGR1022).

We acknowledge support of the publication fee by the CSIC Open Access Publication Support Initiative through its Unit of Information Resources for Research (URICI).

Review statement. This paper was edited by Koen Van Noten and reviewed by Andrea Cannata and Koen Van Noten.

\section{References}

Anthony, R. E., Ringler, A. T., Wilson, D. C., and Wolin, E.: Do Low-Cost Seismographs Perform Well Enough for Your Network? An Overview of Laboratory Tests and Field Observations of the OSOP Raspberry Shake 4D, Seis. Res. Lett., 90, 219-228, https://doi.org/10.1785/0220180251, 2019.

Cadet, H., Macau, A., Benjumea, B., Bellmunt, F., and Figueras, S.: From ambient noise recordings to site effect assessment: The case study of Barcelona microzonation, Soil Dyn. Earthq. Eng., 
31, 271-281, https://doi.org/10.1016/j.soildyn.2010.07.005, 2011.

Cannata, A., Cannavò, F., Di Grazia, G., Aliotta, M., Cassisi, C., De Plaen, R. S. M., Gresta, S., Lecocq, T., Montalto, P., and Sciotto, M.: Seismic evidence of the COVID-19 lockdown measures: a case study from eastern Sicily (Italy), Solid Earth, 12, 299-317, https://doi.org/10.5194/se-12-299-2021, 2021.

Cid, J., Susagna, T., Goula, X., Chavarria, L., Figueras, S., Fleta, J., Casas, A., and Roca, A.: Seismic zonation of Barcelona based on numerical simulation of site effects, Pure Appl. Geophys., 158, 2559-2577, https://doi.org/10.1007/PL00001186, 2001.

Custódio, S., Dias, N. A., Caldeira, B., Carrilho, F., Carvalho, S., Corela, C., Díaz, J., Narciso, J., Madureira, G., Matias, L., and Haberland, C.: Ambient noise recorded by a dense broadband seismic deployment in Western Iberia, Bull. Seismol. Soc. Am., 104, 2985-3007, https://doi.org/10.1785/0120140079, 2014.

Dias, F. L., Assumpção, M., Peixoto, P. S., Bianchi, M. B., Collaço, B., and Calhau, J.: Using Seismic Noise Levels to Monitor Social Isolation: An Example From Rio de Janeiro, Brazil, Geophys. Res. Lett., 47, 1-9, https://doi.org/10.1029/2020GL088748, 2020.

Díaz, J.: On the origin of the signals observed across the seismic spectrum, Earth-Sci. Rev., 161, 224-232, https://doi.org/10.1016/j.earscirev.2016.07.006, 2016.

Diaz, J. and Schimmel, M.: SANIMS [Data set], International Federation of Digital Seismograph Networks, https://doi.org/10.7914/SN/YS_2019, 2019.

Díaz, J., Villaseñor, A., Morales, J., Pazos, A., Córdoba, D., Pulgar, J., García-Lobón, J. L., Harnafi, M., Carbonell, R., and Gallart, J.: Background noise characteristics at the IberArray broadband seismic network, Bull. Seismol. Soc. Am., 100, 618-628, https://doi.org/10.1785/0120090085, 2010.

Díaz, J., Ruiz, M., Sánchez-Pastor, P. S., and Romero, P.: Urban Seismology: On the origin of earth vibrations within a city, Sci. Rep., 7, 15296, https://doi.org/10.1038/s41598-017-15499y, 2017.

Diaz, J., Schimmel, M., Ruiz, M., and Carbonell, R.: Seismometers Within Cities: A Tool to Connect Earth Sciences and Society, Front. Earth Sci., 8, 1-7, https://doi.org/10.3389/feart.2020.00009, 2020.

Green, D. N., Bastow, I. D., Dashwood, B., and Nippress, S. E. J.: Characterizing Broadband Seismic Noise in Central London, Seismol. Res. Lett., 88, 113-124, https://doi.org/10.1785/0220160128, 2017.

Hinzen, K.: Subway-Induced Vibrations in Cologne Cathedral, Seis. Res. Lett., 85, 631-638, https://doi.org/10.1785/0220140003, 2014.

Institut Cartogràfic I Geològic De Catalunya: Catalan Seismic Network, International Federation of Digital Seismograph Networks, https://doi.org/10.7914/SN/CA, 1984.

Krischer, L., Megies, T., Barsch, R., Beyreuther, M., Lecocq, T., Caudron, C., and Wassermann, J.: ObsPy: A bridge for seismology into the scientific Python ecosystem, Comput. Sci. Discov., 8, 1-17, https://doi.org/10.1088/1749-4699/8/1/014003, 2015.

Lecocq, T., Hicks, S. P., Van Noten, K., van Wijk, K., Koelemeijer, P., De Plaen, R. S. M., Massin, F., Hillers, G., Anthony, R. E., Apoloner, M.-T., Arroyo-Solórzano, M., Assink, J. D., Büyükakpınar, P., Cannata, A., Cannavo, F., Carrasco, S., Caudron, C., Chaves, E. J., Cornwell, D. G., Craig, D., den Ouden, O.
F. C., Diaz, J., Donner, S., Evangelidis, C. P., Evers, L., Fauville, B., Fernandez, G. A., Giannopoulos, D., Gibbons, S. J., Girona, T., Grecu, B., Grunberg, M., Hetényi, G., Horleston, A., Inza, A., Irving, J. C. E., Jamalreyhani, M., Kafka, A., Koymans, M. R., Labedz, C. R., Larose, E., Lindsey, N. J., McKinnon, M., Megies, T., Miller, M. S., Minarik, W., Moresi, L., MárquezRamírez, V. H., Möllhoff, M., Nesbitt, I. M., Niyogi, S., Ojeda, J., Oth, A., Proud, S., Pulli, J., Retailleau, L., Rintamäki, A. E., Satriano, C., Savage, M. K., Shani-Kadmiel, S., Sleeman, R., Sokos, E., Stammler, K., Stott, A. E., Subedi, S., Sørensen, M. B., Taira, T., Tapia, M., Turhan, F., van der Pluijm, B., Vanstone, M., Vergne, J., Vuorinen, T. A. T., Warren, T., Wassermann, J., and Xiao, H.: Global quieting of high-frequency seismic noise due to COVID-19 pandemic lockdown measures, Science, 369, 1338-1343, https://doi.org/10.1126/science.abd2438, 2020a.

Lecocq, T., Massin, F., Satriano, C., Vanstone, M., and Megies, T.: SeismoRMS - A simple Python/Jupyter Notebook package for studying seismic noise changes Version 1.0, Zenodo, https://doi.org/10.5281/zenodo.3820046, 2020 b.

Lindsey, N. J., Yuan, S., Lellouch, A., Gualtieri, L., Lecocq, T., and Biondi, B.: City-Scale Dark Fiber DAS Measurements of Infrastructure Use During the COVID-19 Pandemic, Geophys. Res. Lett., 47, 1-8, https://doi.org/10.1029/2020GL089931, 2020.

Mcnamara, D. E., Hutt, C. R., Gee, L. S., Benz, H. M., and Buland, R. P.: A Method to Establish Seismic Noise Baselines for Automated Station Assessment, Seism. Res. Lett., 80, 628-637, https://doi.org/10.1785/gssrl.80.4.628, 2009.

Plaen, R. S. M., Márquez-Ramírez, V. H., Pérez-Campos, X., and Ramón, F.: Seismic signature of the COVID-19 lockdown at the city-scale: A case study with low-cost seismometers in the city of Querétaro, Mexico, 1-17, https://doi.org/10.5194/se-2020-194, 2020.

Poli, P., Boaga, J., Molinari, I., Cascone, V., and Boschi, L.: The 2020 coronavirus lockdown and seismic monitoring of anthropic activities in Northern Italy, Sci. Rep., 10, 1-8, https://doi.org/10.1038/s41598-020-66368-0, 2020.

Raspberry Shake Community: OSOP, S.A., Gempa GmbH, RaspberryShake network, https://doi.org/10.7914/SN/AM, 2016.

Somala, S. N.: Seismic noise changes during COVID-19 pandemic: a case study of Shillong, India, Nat. Hazards, 103, 1623-1628, https://doi.org/10.1007/s11069-020-04045-1, 2020.

Subedi, S., Hetényi, G., Denton, P., and Sauron, A.: Seismology at School in Nepal: A Program for Educational and Citizen Seismology Through a Low-Cost Seismic Network, Front. Earth Sci., 8, 73, https://doi.org/10.3389/feart.2020.00073, 2020.

Wessel, P., Smith, W. H. F., Scharroo, R., Luis, J., and Wobb, F.: Generic Mapping Tools: improved version released, Eos, 45, 409-410, https://doi.org/10.1002/2013EO450001, 2013.

Xiao, H., Eilon, Z. C., Ji, C., and Tanimoto, T.: COVID19 Societal Response Captured by Seismic Noise in China and Italy, Seismol. Res. Lett., 91, 2757-2768, https://doi.org/10.1785/0220200147, 2020. 